\title{
Condições Higiênico-Sanitárias de Instituições de Ensino: É Possível Adequá-Las?
}

Angélica Pereira Nery (I), Monise Viana Abranches (I), Tatiana Bering (II), Daniela Alves Silva (III), Paula Moreira Tagliassachi (I), Caline Pereia Cardoso (I)

(I) UFV - Universidade Federal de Viçosa campus de Rio Paranaíba (Caixa Postal 22), (II) UFMG Universidade Federal de Minas Gerais (Av. Alfredo Balena, 190 - Campus Saúde 30130-100 Belo Horizonte - MG), (III) UFES - Universidade Federal do Espirito Santo (Caixa Postal 1-9011)

\section{Resumo}

Introdução: O Programa Nacional de Alimentação Escolar visa promover o desenvolvimento de crianças e adolescentes e melhorar o rendimento escolar. Nesse contexto, os manipuladores de alimentos tem papel primordial na adequação das condições higiênico-sanitárias das cantinas. Esse estudo objetivou avaliar as condições higiênico-sanitárias de cantinas escolares da rede estadual de ensino, localizadas em um município da região do Alto Paranaíba, MG, antes e após a capacitação dos colaboradores. Materiais e Métodos: As cantinas avaliadas $(n=2)$ pertencem à instituições que atendem adolescentes (Escola A) e crianças (Escola B). A avaliação foi realizada antes e após o período de capacitação dos colaboradores com aplicação de uma lista de verificação, adaptada para esse tipo de serviço. A lista incluiu 98 itens subdivididos nos seguintes blocos: condições das instalações e edificações; controle de vetores e pragas; qualidade da água e esgoto; manejo de resíduos; equipamentos, móveis e utensílios; higienização de equipamentos, móveis e utensílios; recursos humanos e produção de refeições. O percentual de adequação foi calculado considerando o total de itens julgados e o número de quesitos adequados. As cantinas foram classificadas em: Grupo 1 (Bom); Grupo 2 (Regular) e Grupo 3 (Ruim), segundo o percentual alcançado. Os temas abordados nos treinamentos foram: higiene pessoal; higiene ambiental; boas práticas no processo de produção das refeições e importância da

\footnotetext{
Referência:

Angélica Pereira Nery, Monise Viana Abranches, Tatiana Bering, Daniela Alves Silva, Paula Moreira Tagliassachi, Caline Pereia Cardoso.Condições Higiênico-Sanitárias de Instituições de Ensino: É Possível Adequá-Las?. In: Anais do 12 을 Congresso Latinoamericano de Microbiologia e Higiene de Alimentos - MICROAL 2014 [= Blucher Food Science Proceedings, num.1, vol.1]. São Paulo: Editora Blucher, 2014. DOI 10.5151/foodsci-microal-030
} 
alimentação escolar. Discussão dos Resultados: A capacitação foi eficiente em contribuir para o aumento do conhecimento tanto na Escola A, onde $63,6 \%$ das oficinas aumentaram o conhecimento dos manipuladores, quanto na Escola B, onde 100,0\% das oficinas contribuíram para o aprimoramento profissional. Quanto às condições higiênico-sanitárias, na Escola A, a adequação passou de 66,3\% para 75,5\% e na Escola B passou de $61,2 \%$ para $74,5 \%$. Os blocos que apresentaram melhorias em ambas as instituições foram referentes às condições das instalações e edificações, dos equipamentos, móveis e utensílios e produção de refeições. Conclusão: As cantinas escolares concentram muitas irregularidades quanto às condições higiênico-sanitárias. Todavia, parte dos problemas pode ser solucionada por meio da capacitação dos colaboradores, uma estratégia simples e de baixo custo, visando promover a segurança das refeições produzidas.

Palavras-Chave: Treinamentos, Manipuladores de alimentes, Segurança alimentar

Agência de Fomento: UFV 